\title{
Adaptive Asset Management for Flood Protection: The FAIR Framework in Action
}

\author{
Bart Vonk ${ }^{1}$, Wouter Jan Klerk ${ }^{2,3, *}$, Peter Fröhle ${ }^{4}$, Berry Gersonius ${ }^{5}$, Frank den Heijer ${ }^{2,6}$, \\ Philipp Jordan ${ }^{4}$, Ulf Radu Ciocan ${ }^{7}$, Jeroen Rijke ${ }^{6}$, Paul Sayers ${ }^{8}$ and Richard Ashley ${ }^{9}$ \\ 1 Rijkswaterstaat, P.O. Box 2232,3500GE Utrecht, The Netherlands; bart.vonk@rws.nl \\ 2 Deltares, Boussinesqweg 1, 2629HV Delft, The Netherlands; frank.denheijer@han.nl \\ 3 Department of Hydraulic Engineering, Faculty of Civil Engineering and Geosciences, Delft University of \\ Technology, Stevinweg 1, 2628CN Delft, The Netherlands \\ 4 Institute of River and Coastal Engineering, Hamburg University of Technology, Denickestraße 22, \\ 21073 Hamburg, Germany; froehle@tuhh.de (P.F.); philipp.jordan@tuhh.de (P.J.) \\ 5 ResilienServices, 2613PN Delft, The Netherlands; berry@resiliense.nl \\ 6 Sustainable River Management Group, HAN University of Applied Sciences, Ruitenberglaan 26, \\ 6826CC Arnhem, The Netherlands; j.rijke@han.nl \\ 7 Danish Coastal Authority, 7620 Lemvig, Denmark; rci@kyst.dk \\ 8 Sayers and Partners, Watlington OX49 5PY, UK; paul.sayers@sayersandpartners.co.uk \\ 9 EcoFutures Ltd., 3 Greendale Court, Honley, Holmfirth, West Yorkshire HD9 6JW, UK; \\ r.ashley@sheffield.ac.uk \\ * Correspondence: wouterjan.klerk@deltares.nl
}

Received: 29 October 2020; Accepted: 1 December 2020; Published: 3 December 2020

\begin{abstract}
Uncertainties about climate change consequences, changing societal requirements and system complexity require flood protection asset managers to continuously evaluate their asset management policies and practice to manage risk and improve the resilience of their assets. However, there are many challenges in doing this, with asset operators often facing conflicting interests and major uncertainties about the future needs for asset performance. In the EU Interreg IV FAIR project, flood protection asset owners and operators, with scientific partners from the North Sea Region of Europe collaborated to develop practical guidance for adaptive asset management of flood protection infrastructure. The central component of this guidance is the FAIR framework, presented here. The framework combines insights and principles from ISO 55000 on asset management and ISO 14090 on climate adaptation with asset operator experiences to provide a practical guide for integration of asset management considerations within both strategic and operational contexts via a tactical handshake. This is a means to avoid the common lack of connection between strategic plans and operational practice. The applicability of the framework is illustrated with examples from Pilot Cases within the FAIR project, in which its value in terms of improved asset management and reduced costs has been demonstrated.
\end{abstract}

Keywords: asset management; climate change adaptation; flood risk; operation; strategy; prioritization

\section{Introduction}

Interest in asset management as a formalised means of managing assets has increased significantly. ISO 55000 defines asset management as "the coordinated activity of an organization to realise value from assets" [1]. It is thus a systematic approach to ensure that throughout the whole life cycle of an asset, or group of assets, the investment costs, the performance achieved and the risks faced are balanced. Several approaches have been developed that are well aligned with the principles of asset management, such as the development of Reliability-Centred Maintenance (RCM), in the context 
of aviation maintenance [2], and the development of Risk Based Inspection (RBI), in an industrial context [3]. Both of these have contributed to the alignment of performance requirements and efforts in terms of maintenance. The added perspective from recent asset management developments to these approaches has been primarily to ensure that not only are operational aspects considered, but also the strategic and tactical aspects $[4,5]$. This addresses how a performance requirement is to be met and also includes consideration as to what the requirement should be and why. Many practical asset management challenges are defined in the context of life-cycle management, which is the integrated management of assets over their whole life-cycle based on performance, risk and cost [5]. This is thus a very important subject of asset management.

In the context of flood protection, assets are primarily drains, dikes, dams, dunes, storm surge barriers and other hydraulic structures. Asset management for these requires a means to align reinforcement and renovations with maintenance and inspection efforts while ensuring that a variety of performance requirements required by society are met for the foreseeable future and beyond. Requirements can be acceptable risk levels, reliability targets or other factors such as the influence on existing ecosystems or the number of additional functions an asset provides [6]. The latter is especially of interest as many assets have multiple functions, for instance, nature-based solutions for coastal protection (e.g., salt marshes [7]) also provide ecosystem services. The requirements for various functions will change over time depending on e.g., changing societal preferences, technical innovations or changes to environmental boundary conditions.

A key aspect of managing systems of flood protection is adaptiveness [8]. Many flood asset systems have been developed over centuries, and now face large uncertainties to the extent and influence of climate change and other societal effects on long term planning. Adaptiveness is therefore a key consideration in asset management, and pivotal to ensure the future resilience of flood protection systems [9]. ISO 14090 provides guiding principles [10] for adaptation to climate change that has been applied to flood protection in the past. However, this has not been an explicit consideration in the context of asset management as defined by ISO 55000. For instance, Kwadijk et al. [11] demonstrated the viability of different strategies for delta management in The Netherlands for a set of possible futures, and Haasnoot et al. [12] continued this in the context of extreme Sea Level Rise as a consequence of potential Antarctic ice sheet disintegration. Typically such strategic analysis includes adaptation pathway analysis as a method to identify the robustness and resilience of strategies over the longer term, and this clearly demonstrates the need to look at adaptiveness in the context of asset management.

In practice, it is found that the strategic planning of asset management (the why and what) is often not well aligned with the operational asset management (the how), which concerns, for instance, the inspection and maintenance of assets $[5,13,14]$. Tackling this divide between strategic and operational asset management has been one of the core goals and outcomes of the FAIR (Flood infrastructure Asset management \& Investment in Renovation, adaptation, optimization and maintenance) project.

FAIR was an EU part-funded project in which various partners and flood risk asset owners from Belgium, Denmark, England, Germany, Norway, The Netherlands and Sweden collaborated to improve adaptive asset management for flood protection. FAIR addressed the joint challenge of investing in ageing flood protection infrastructure and taking into account uncertainties such as climate change, demographic changes and/or economic developments. A major challenge in doing this is how to relate strategic long-term planning questions to "everyday" operational asset management, and vice versa. In addressing this challenge, FAIR has formulated both a policy framework [15] and a technical framework for the delivery of adaptive asset management. The focus of this paper is on the technical framework. The main goals within the FAIR project are that: (i) the available budgets for the asset owners can be used 5\% more efficiently; (ii) the lifespan of the infrastructure managed can be extended by at least $5 \%$ to buy time to reduce uncertainties; (iii) the value of the infrastructure is enhanced to include further functions and benefits, such as economic (e.g., tourism), ecological or social value.

This objective of this paper is to outline the formulation and demonstrate the applicability and use of the technical framework developed in the FAIR project. The framework uniquely helps 
asset managers to combine the general AM procedures outlined in ISO 55000 with the guidance for adaptation provided by ISO 14090, and aligns the contexts of strategic, operational and tactical asset management for flood protection assets. Section 2 outlines the development of the framework and how it utilises the ISO guidelines. Section 3 presents specific applications in the context of strategic, tactical and operational asset management and further specifies the different parts of the framework. Sections 4 and 5 give a discussion and conclusions on applicability and further development needs.

\section{A Framework for Adaptive Asset Management of Flood Protection}

The FAIR framework (Figure 1. The FAIR framework for adaptive asset management [16]. It relates different components of asset management decision making in strategic, tactical and operational decision contexts, as well as principles for adaptation to climate change from ISO 14090 [10].) seeks to link strategic, tactical and operational aspects of (flood protection) asset management (a framing also recognized in ISO 55000 and by the Institute of Asset Management [4,17]). Within the FAIR framework, the strategic context refers to the adaptive management planning process, the operational context focuses on delivering and informing the adaptive plan, and the tactical context refers to the "handshake" between the two. The framework helps "translate" operational findings into strategy, and in turn "translate" the strategy in actionable operational planning and requirements.

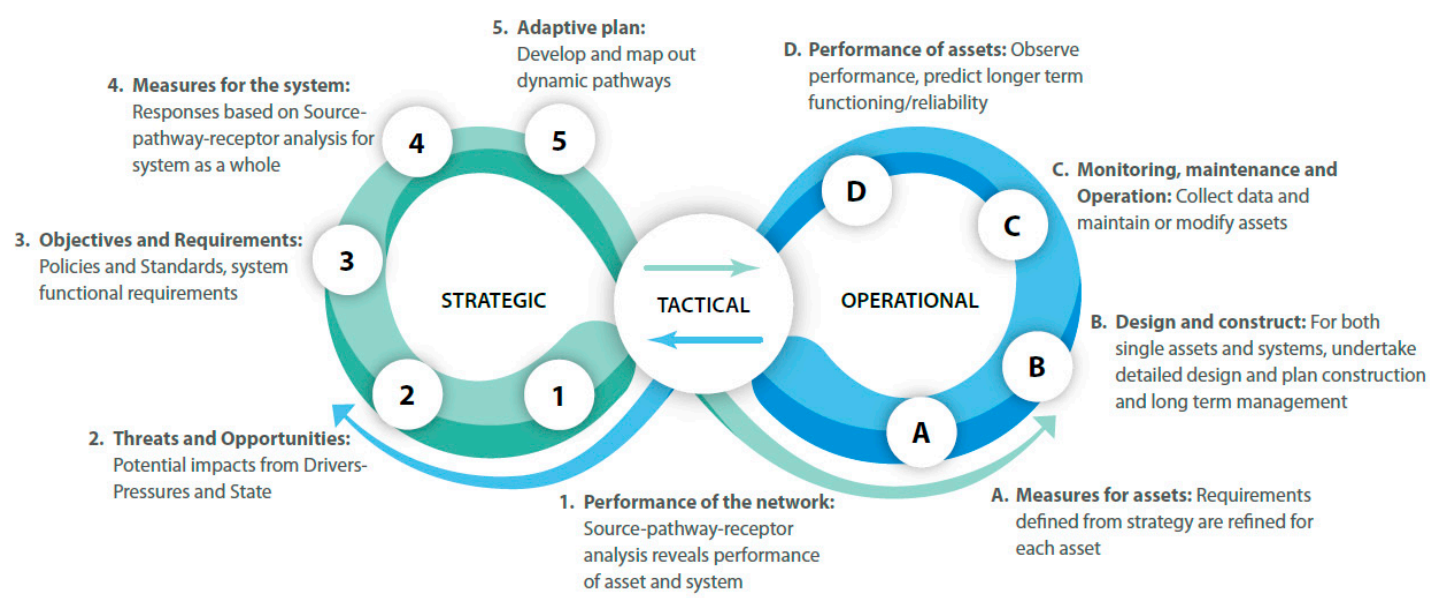

Figure 1. The FAIR framework for adaptive asset management [16]. It relates different components of asset management decision making in strategic, tactical and operational decision contexts, as well as principles for adaptation to climate change from ISO 14090 [10].

The FAIR framework has been developed through a collaboration between domain expertise and practitioner expertise. These have included expert workshops [16] and several pilot studies (see Figure 2) to understand the real-world challenges and best practice asset management approaches in flood management [18,19], in water and wastewater [20], and general public infrastructure [5]. Through the FAIR workshops and pilot studies, these approaches have been extended to explicitly consider a hierarchy of temporal and spatial scales and, crucially, the central role of the "tactical handshake" as a pre-requisite for effective, efficient and adaptive asset management in practice. In so doing, FAIR supports the translation of IS0 55000 into the flood risk management context, recognizing that effective flood risk management relies upon good asset management (as recognized by the Environment Agency in successfully attaining ISO 55000 accreditation (Environment Agency, 2015)). 


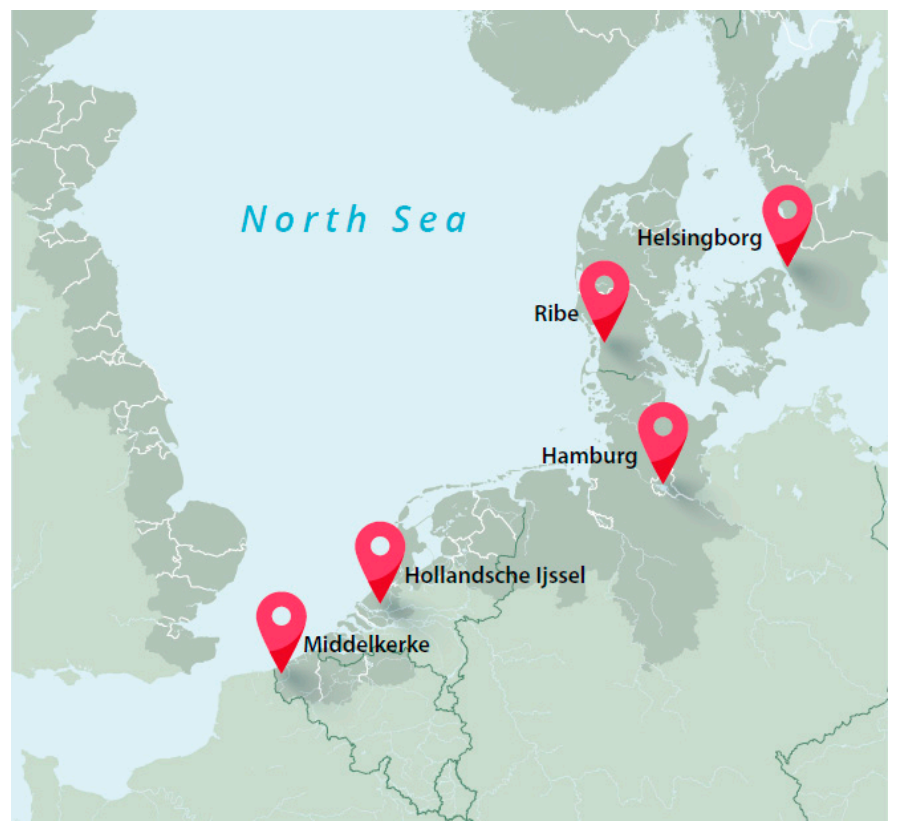

Figure 2. Overview of the case study locations of the EU Interreg FAIR project [16].

The FAIR framework supports the delivery of flood protection as a multi-stakeholder endeavour and one that brings together issues of placemaking (through spatial planning), investment and aesthetics as well as notions of acceptable risk, resilience and ecosystem health e.g., [21]. Asset managers seek to provide flood protection in a way that balances these perspectives through a transparent process of trade-offs relating to life-cycle cost [5], life cycle risk and life cycle performance at multiple scales: spatially-from a single asset and to the system of assets-and temporally-from short to long term; a process familiar to all asset managers and reflected in ISO 55000. The FAIR framework reflects this long-term perspective through embedding a process of continuously gathering data and information, and recurring analysis, adjustment and adaptation of policies and assets (including modifying the probability of flooding and its severity as well as the vulnerability and resilience of the receptors threatened e.g., [22]). To enable these connections in practice, and ensure these processes are appropriately linked, four "principles of good practice" emerged through the collaborative process:

1. Frequently re-evaluate the performance, risk and costs across the asset system as well as the AM processes in place.

2. Define hierarchical metrics (indicators) and assessment criteria that reflect the desired outcomes from the strategic, operational and tactical contexts.

3. Consider multiple temporal and spatial scales and take appropriate action to manage assets across these scales.

4. Understand the physical context, management, ownership and legal context of all assets within the system (individually, collectively or interactively).

Further details of the planning and decision contexts and the various components 1-5 and A-D are provided in the next section. It has to be noted that a specific situation can result in a different starting context. Therefore, the perspectives from each of these contexts are explained and illustrated using some of the Pilot Cases from the FAIR project.

\section{Putting the Framework in Action}

Five Pilot Cases were studied in the FAIR project, putting the FAIR framework into action. These help to demonstrate the applicability of the framework in day-to-day asset management for flood protection in different countries of the North Sea Region (NSR) see Figure 2 for the Pilot Case locations. The Pilot Cases reflect the diversity of existing flood protection structures and different 
national or regional strategies and practices in asset management in the NSR. Thus, not every case covers all components of the framework, but rather focuses on the part that is currently critical in a given context. Table 1 provides a short description of each Pilot Case and indicates the focus area.

Table 1. Overview and brief description of Pilot Cases in the FAIR project. The decision context indicates which asset management context the Pilot Case focuses on primarily (strategic/tactical/operational), the last column gives a brief description of the case and its main aspects. Some cases covered different angles and might occur twice.

\begin{tabular}{|c|c|c|}
\hline Pilot Case & Decision Context & Description and Main Topics \\
\hline \multirow{2}{*}{ Ribe (Hvide Sande), Denmark } & Strategic & $\begin{array}{l}\text { Discussion on safety standards; Improved adaptation of flood } \\
\text { protection to future climate through systems analysis and } \\
\text { development of adaptive pathways. }\end{array}$ \\
\hline & Tactical & $\begin{array}{l}\text { Develop a coordination and planning strategy with regards to } \\
\text { maintenance and administration of flood defence } \\
\text { infrastructure; management of diverging stakeholder interests. }\end{array}$ \\
\hline \multirow[b]{2}{*}{ Helsingborg, Sweden } & Strategic & Introduce long term strategy for dealing with climate change. \\
\hline & Operational & $\begin{array}{l}\text { Search for practical guidelines for the redesign of the city, that } \\
\text { help include FRM in other infrastructure developments. }\end{array}$ \\
\hline $\begin{array}{l}\text { Hollandse IJssel, } \\
\text { The Netherlands }\end{array}$ & Tactical & $\begin{array}{c}\text { System-approach; trade-off costs and benefits between dike } \\
\text { and barrier improvements to reduce whole lifecycle costs of } \\
\text { flood protection system; prioritizing dike } \\
\text { reinforcement projects. }\end{array}$ \\
\hline Middelkerke, Belgium & Operational & $\begin{array}{l}\text { Design of an adaptive, nature-based flood defence which can } \\
\text { deal with climate-change-induced future developments. }\end{array}$ \\
\hline Hamburg, Germany & Operational & $\begin{array}{l}\text { Analysis of maintenance processes and strategies to improve } \\
\text { maintenance with respect to cost reduction and optimal } \\
\text { investment; develop a risk-based maintenance strategy and a } \\
\text { web-based "Dike Information System" (DIS) incorporating all } \\
\text { relevant flood protection data. }\end{array}$ \\
\hline
\end{tabular}

None of the pilots covers the entire FAIR framework. The pilots have been selected based on the range of their different stages in AM (operational/strategic/tactical), the type and location of defences, and the governmental complexity. For example, the Ribe pilot is about a tidal/river system interaction where there is not yet a clear view on threats and opportunities, and for which different stakeholders with a variety of interests (flood protection, nature, fishery) need to find the best way how to combine their interests in an integrated system approach. However, there are no safety requirements specified, so the main focus of the pilot is on defining threats and opportunities, and from here derive system requirements and strategic alternatives for future adaptation. In the Hollandse IJssel Pilot Case, an assessment showed that the dike on the river the IJssel does not meet existing safety requirements. Through close collaboration between the authorities managing the dikes and the storm surge barrier, an integral approach was found that aids in optimizing investments in the storm surge barrier and dikes, leading to a more efficient asset management strategy. Here the focus was much more on aligning strategic interests (i.e., breaking free from the individual organisational silos) with operational interventions through the tactical handshake. The pilot in Hamburg focused on the operational asset management of gates in the sea walls, with a major focus on ensuring the reliability of the gate operation and relating this to maintenance and inspection measures. These are just some examples of the diversity of practical situations that can be encountered and that can be streamlined by the FAIR framework.

\subsection{The Framework in Action from a Strategic Starting Point}

The main challenges within the strategic context should be to establish the overall strategy-including norms, legislation and policy-and long-term planning processes that follow. For this purpose, the strategy should use an overall integrated system perspective aimed at understanding and integrating knowledge 
on threats, asset operational effectiveness, responsive policy, standards and interactions within flood protection systems and their physical context. A strategy defines priorities for investment goals to be used in the tactical handshake as a basis for prioritization based on cost, risk and performance. These are driven from an understanding of the flood risks, the opportunities associated with alternative strategies, objectives and functional requirements, and the performance of alternative adaptation measures necessary to achieve these. The strategic components in the FAIR framework (Figure 1) are as numbered:

1. Performance of the network: This component receives information from component $D$ in the operational loop, via the tactical handshake. This provides the observed performance and predictions of longer-term functioning/reliability essential for use in the source-pathway-receptor (SPR) analysis to reveal the performance of the assets and system as a whole and their longer-term functioning.

2. Identifying threats and opportunities: This requires consideration of both external (e.g., climatic, socio-economic) and internal (e.g., asset and asset network functioning) factors. Understanding the opportunities and threats for individual assets and also system/strategic contexts, enables asset managers to plan ways to optimise investments for the operational context. It enables the take-up of opportunities (e.g., multi-functionality of services) and minimises the risks from threats cost-effectively.

3. Setting strategic asset management objectives and requirements: This component aims to establish the desired role that flood protection assets play today and, in the future, their performance objectives, and the likely investments in a way that delivers multi-value outcomes and that can be appropriately adapted in the future. Strategic objectives must seek to reflect local and national needs, align multi-institutional and stakeholder interests and set out the performance objectives. This should take into account funding arrangements, roles and responsibilities.

4. Understanding the technical performance of the system and system measures: Good decisionmaking relies upon an understanding of the behaviour of the asset system. This includes developing an understanding of:

- The geographical boundaries of the system, the vulnerabilities to flooding within that system;

- The external influences that may influence the behaviour of the system over time;

- The hydrological and hydraulic functioning of the system;

- The performance of assets in response to the loads and future climate change;

- Inherent uncertainties within the data, models and model structures;

- The user of the system and their interests, such as heritage protection or ecosystem management.

The Source-Pathway-Receptor (SPR) model (as applied to flood management) [23], provides a practical means of disaggregating the basic components of probability and consequence into their constituent components. Consideration is given to both the probability of the initiating event (the source of the flood) and the probability that floodwaters will reach a particular location, taking account of the performance of the intervening system (the pathway of the floodwater). The consequences if flooding occurs reflect both the vulnerability of the receptors and the chance that a receptor will be exposed to the flood.

5. Developing an adaptive asset management plan: Strategic plans should proactively plan for an uncertain future and can be modified periodically (e.g., every 10 to 20 years), and as new evidence and insights emerge. Investments in monitoring and evaluation provide the central underpinning of the process of updating both the strategy and the operational delivery to ensure flood risks are well-managed and plans adapted in a timely manner.

An application of the framework focused on strategic aspects is given in the next section. 
Pilot Case in Ribe, Denmark: From Static/Hold-the-Line Thinking to Dynamic Planning

The town of Ribe (Municipality of Esbjerg) is subject to multiple sources of flooding. To the west, a dike protects the town and its surroundings from flooding from the Wadden Sea. Climate change will put pressure on this dike through sea-level rise and increased storminess. Two streams flow through the pilot area: the Rivers Ribe and King. These cross the dike through sluices. In the winter season, large amounts of water are present in the polder, that need to be discharged through the sluices. However, due to high water levels at sea, the sluices have to close frequently. As pressures on the system will increase in the future a change of strategy is required. This is constrained by the limited availability of funding and the system complexity. The structured approach in FAIR has helped develop a good understanding of (i) existing assets and their co-dependencies in a system context; (ii) The sources of flooding, (iii) Flooding mechanisms, (iv) How requirements can be set (Denmark does not have a national standard) and (v) Risk and acceptable risk.

Conventional approaches to asset management in Denmark adopt fixed timeframes following national guidelines and driving operational decisions that typically lead to "hold-the-line" policies, i.e., focused on maintenance of existing measures and not incorporating potential climate change impacts. New methods promoted through FAIR such as dynamic pathway planning [11] (see Figure 3) enable a more coherent strategic approach, that incorporates multiple aspects of planning at a system level. An SPR analysis has highlighted new pathways for how the flood protection systems may respond, based on, among other things: outside pressures on the system (climate change, urban development), planning cycles (local planning, political cycles) and socioeconomic considerations. The possible responses as considered in the dynamic pathway planning derive from multiple considerations such as moving the economic focus of some areas from farming to tourism. As such the dynamic pathway planning provides a strategic structure for the viability of different future strategies in the area of Ribe. Integrated hydrodynamic modelling incorporating sea levels, river discharges, groundwater levels and precipitation are becoming key components in the planning toolbox, and a common understanding of the performance of all assets are important prerequisites of any future work and application of this in prioritization of interventions.

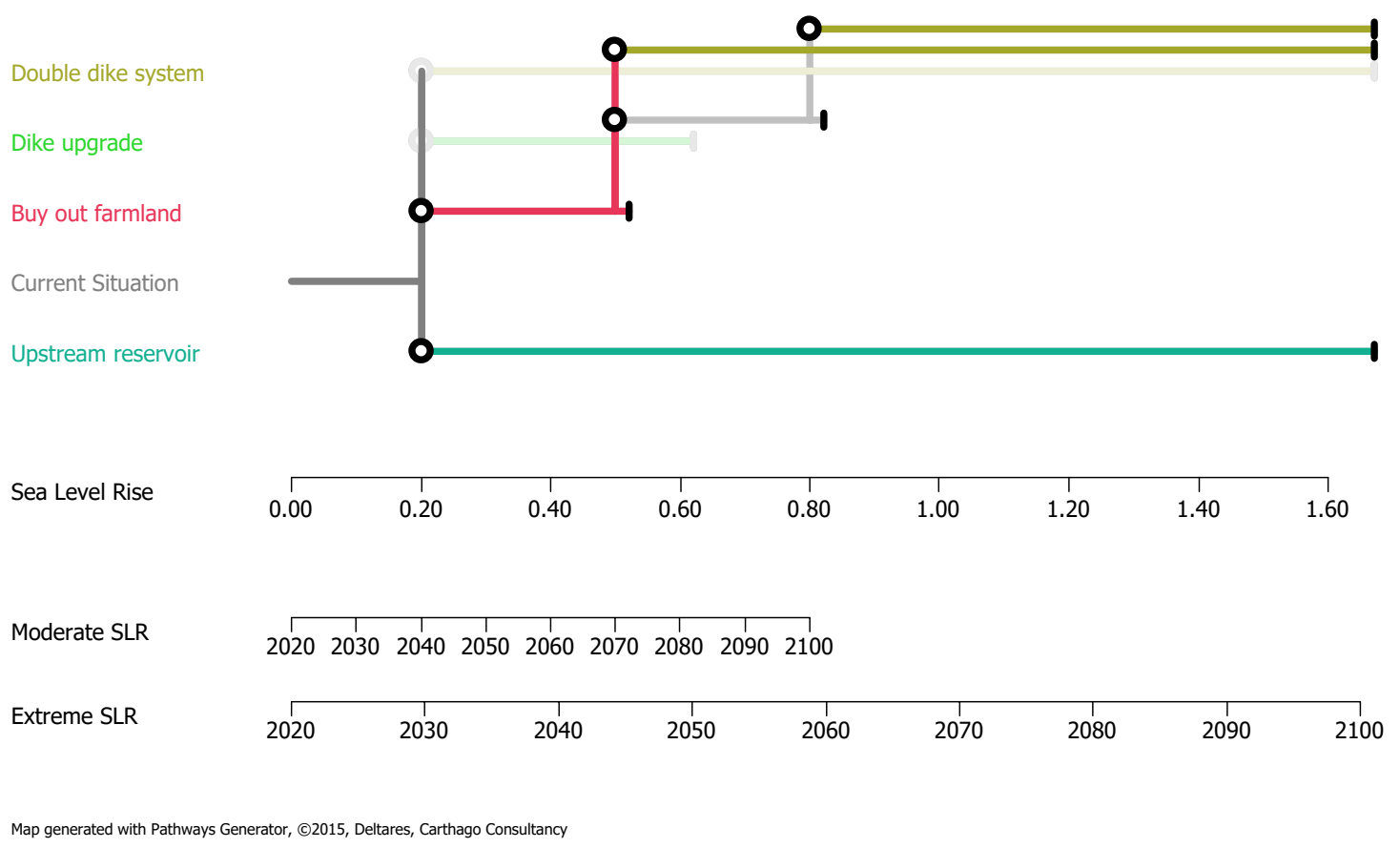

Figure 3. Initial consideration of adaptative pathways developed through collaborative working with the FAIR science and local authority partners [24]. 


\subsection{The Framework in Action from an Operational Perspective}

Flood protection assets are either operated by their respective private owners or, like in most cases in the North Sea Region (NSR), by public authorities. Within the operational decision context, asset management is handled very differently by the authorities involved in FAIR, ranging from contracting private companies for most measures to performing all major operational tasks with in-house staff and experts [25]. In general, Operational Asset Management (OAM) represents a broad range of tasks and measures performed by the flood protection authorities. Compared with the strategic measures, these measures have short planning horizons and a limited spatial scale. Operational measures depend on feedback from inspections and field tests. In the context of a constant improvement process for flood protection assets, OAM provides crucial information for design and construction. Within FAIR this scope of activities and duties is considered in the four major components depicted in the operational loop of the framework (see Figure 1: A. Measures for assets; B. Design and construct; C. Monitoring, maintenance and operation (MMO); D. Performance of assets.

The adaptive (strategic) plan needs to be refined to define actual measures for assets (component A) of the OAM loop. Through the tactical handshake, strategic objectives are translated to asset-specific requirements and interventions. These include requirements for key tasks such as flood preparedness for extreme events, data and information management or the implementation of relevant European Directives. Additionally, requirements for reliability can be defined based on the "translation" from required network reliability to asset reliability e.g., [26]. The inclusion of other environmental or societal dimensions and requirements must also be considered especially where the asset provides multiple functions.

Design and construction (B) of the selected options for the individual assets are based on several principles and functional requirements, depending on the local conditions and the dominant factors the design is intended to address. General guidelines for the design and construction of flood protection assets are defined in numerous national or international codes, standards and technical rules but can vary for flood protection. For instance, The Netherlands uses flood probability standards [27], whereas in Belgium design storms with certain exceedance probability are used and the UK uses a cost-benefit oriented approach (for public expenditure, [28]). Regardless of these and other national differences, the three underlying core principles of FAIR when it comes to design and construction-multifunctionality, bridging the gap between design and maintenance and taking a long-term perspective incorporating adaptability-were addressed in the activities around the FAIR pilots.

Apart from day to day operation, flood protection assets primarily must be fully functional when needed. This requires an in-depth knowledge of their mode of operation. In FAIR, critical pathway analysis was found to be a valuable tool to identify essential processes in operation of assets and thus, to address possibilities to overcome unwanted impacts for the operation over time. In the absence of extreme events like floods, operations are mostly confined to regular maintenance. The main goal of maintenance is to preserve or improve a defined target state of an asset to ensure its desired functionality (see e.g., DIN 31051:2012-09), considering the requirements, and enabling assessment of an FP asset performance. Most of the FAIR partners rely on condition-based maintenance which depends on a profound knowledge of the FP asset status and the relevant boundary conditions. Therefore, monitoring is an integral part of the whole process. Mostly through comparatively low effort checks, the status and condition of the FP asset as well as the frequency and intensity of loads are monitored regularly. Managing the collected data and providing access to it is one of the key tasks for OAM.

The assessment of the asset performance (D) directly depends on the findings from Maintenance, monitoring and operation. This feedback is considered in performance assessments in various ways by the FAIR partners. In The Netherlands for example, the authorities follow a model-oriented approach, developing statutory safety assessments for their FP assets see e.g., [26,27]. The UK, however, relies on a more pragmatic, condition-based assessment, where experienced surveyors assess an asset-based on predefined criteria and condition levels, which are described in the Condition Assessment Manual [29]. 
In Germany and Denmark, regularly scheduled inspections, as well as on-site analysis by a group of experts, are used for the performance analysis. In general, the complexity of the performance assessments is tuned to the FP values and risks in the protected areas as well as to the complexity of the FP structure. The multitude of individual performance assessments will then translate to an evaluation of the overall network performance and thus provide input for strategic asset management, thus assisting with the evaluation of whether the chosen strategy works out well in practice or needs to be reconsidered.

Pilot Case in Hamburg, Germany: Integrating Data and Observations to Support Operation \& Maintenance

Data management is one of the major challenges that operating authorities with numerous flood protection assets must deal with. On-site analysis and tests, performance assessments, inspections and expert surveys generate a large amount of different types of data. When stored and managed in an ordered manner, and made accessible to all employees of the operating authority, this data poses an extensive added value to Operations \& Maintenance, providing all relevant information on an asset instantly. In the FAIR project the local authority (Agency for Roads, Bridges and Waters; LSBG), owner of the Hamburg Pilot Case has been developing a central module for the presentation of all relevant data for the city flood protection facilities- the Dike Information System, DIS (see Figure 4). This tool provides planners, designers and maintenance personnel comprehensive information about a specific asset, thus facilitating their daily work. Challenges that had to be overcome in the process were the determination of the data structure itself, the avoidance of redundancies and the conversion of the data itself as much of it was only available on paper. As the DIS is web-based, it is available in the office as well as in the field, e.g., during an on-site inspection. LSBG is confident that the DIS will lead to a significant improvement to Operation \& Maintenance practice. Thus enabling better-informed decision making, better monitoring of performance and thus improving asset management practice. The insights into performance provided by the DIS can add value to strategic asset management in the Hamburg region as there is a more structured platform for translating asset to network performance.

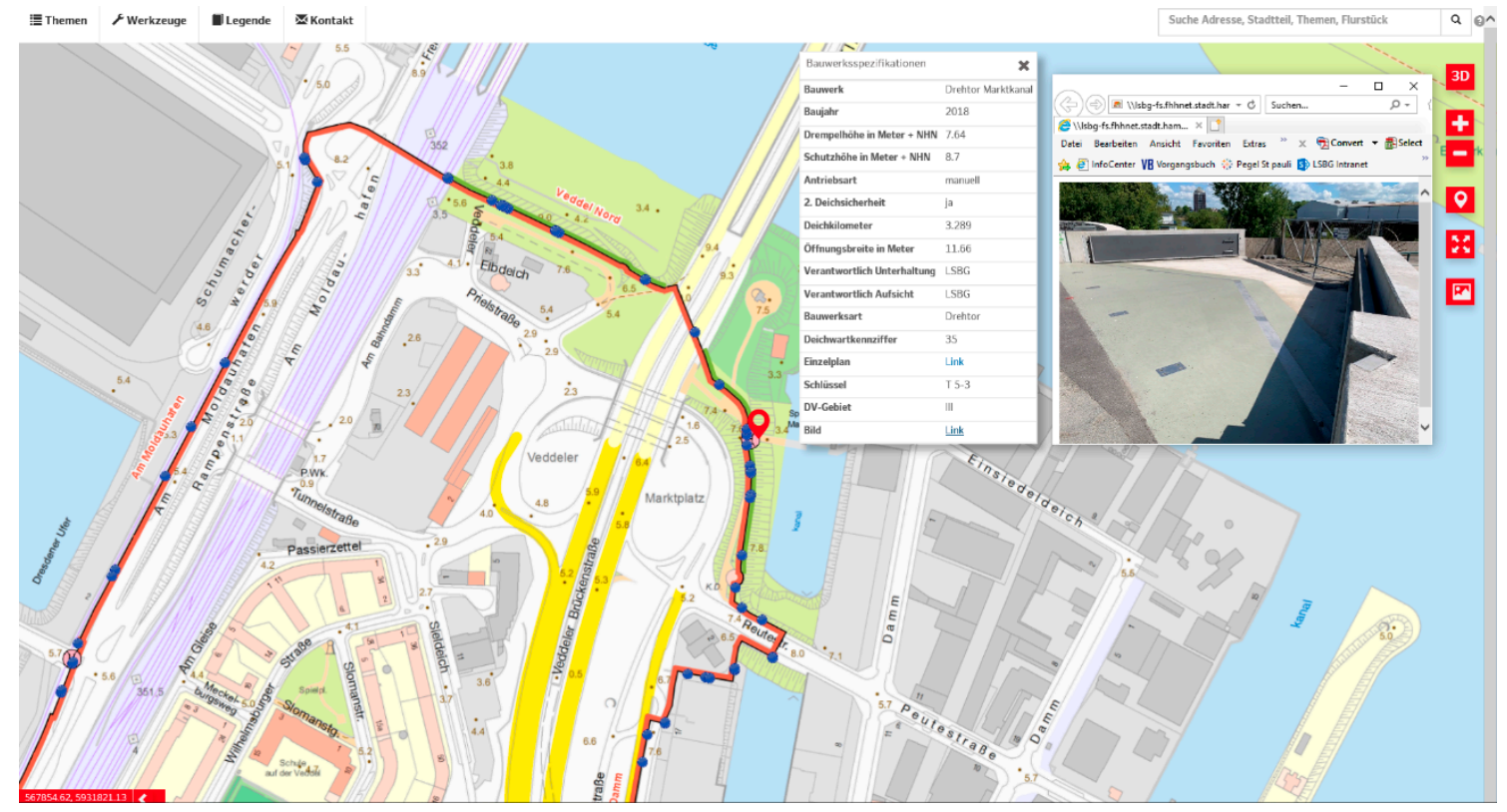

Figure 4. Screenshot from the Dike Information System displaying structural details and an image of the turning gate "Marktkanal" on the island of Veddel in the surrounding harbour area of Hamburg (courtesy of LSBG, Hamburg). 


\subsection{The Framework in Action: Connecting Strategic Goals to Operational Action through the Tactical Handshake}

The tactical asset management decision context acts as the handshake between the operational and strategic contexts. The tactical decision context needs to translate strategic plans to establish the boundary conditions in space and time for the operational decision context. Prioritisation and programming are key elements in this translation from strategic plans to operational delivery. Translation of performance of single assets to system/network performance forms the link from operational to strategic processes. There are five key aspects in this vice versa translation:

- Re-evaluation of the tactical handshake, or how well strategy relates to practicable operational delivery and vice versa. These re-evaluations can trigger the need to reconsider strategies or adapt operation.

- Scale (temporal and spatial): while operational asset management tends to look at shorter time horizons and smaller systems, strategic asset management is more concerned with long term adaptation to cope with developing threats and utilize arising opportunities.

- Enabling implementation: the tactical handshake should align and point to the different requirements and desires from different functions and their practical consequences.

- Use appropriate metrics: a major factor in the success of the tactical handshake is whether the metrics used for translating strategic to operational decisions (and vice versa) are fit-for-purpose and result in the desired effects on asset and network performance.

- Looking beyond the management scope: a major challenge in the tactical handshake is that strategic and operational contexts of AM may be the responsibility of different organisations.

In the FAIR framework, the first main task of tactical asset management is the translation of an adaptive plan at the system level to defined measures for assets (5 to A in Figure 1). In this, the strategic plan is translated into asset-specific measures, such that potential constraints in terms of budget or capacity are dealt with using an assigned prioritisation. It is possible that the strategic plan might not be practically feasible immediately. This is one of the core tasks of the tactical handshake: to align strategic goals to deliver actual measures in the operational process that fit the available resources.

The link from operational delivery to input for strategic planning is represented by the translation of the performance of single assets to system/network performance (D to 1 in Figure 1). Of particular importance is that the operational asset performance assessment includes all aspects relevant for determining the network performance. For a dike ring area, this should include all possible modes of failure for every section and component. The time horizon of the performance assessment is of importance, as performance assessments typically have time horizons of less than 12 years (in FAIR cases), but strategic plans typically extend far longer than this. This disparity should be addressed in this component, either by changing requirements for the operational performance assessment or by translating the monitored results into a longer-term prediction of network performance.

The practical success of the tactical handshake depends upon the capacity to implement the translation of strategic plans to operational delivery and vice versa. This depends strongly on the following points:

- For the re-evaluation of the tactical handshake, it is critical to ensure stable funding for a defined and confirmed period for delivering projects. However, there needs to be sufficient flexibility to cope with changes arising from the strategic context or implementation issues encountered in operational delivery. This is often found to be a challenge, especially organisationally. For many areas, there are multiple actors with different responsibilities and different strategic goals, who each have limited budgets. Even if responsibilities are based within a single organisation, there are often multiple internal silos that create false barriers.

- Different functions often have different responsible actors, also in terms of funding sources or allocations. The tactical handshake needs to map the different utilities and functions, clearly showing 
who is interested, who benefits and who pays. This added analytical complexity is a significant challenge in the allocation of resources, especially as funders typically do not understand the need to do this beyond their own immediate interests.

- The use of various and different metrics to assess the value and benefits from AM investments can cause confusion, disagreement and misunderstanding. In many applications, different ways of assigning priority and value are used by each major stakeholder. Overall, as called for by CIRIA (2013) and others, any metrics need to be standardised and formalised in an agreed format by all players.

- A challenge in AM decision making is to properly account for benefits that might not directly benefit the asset owner. The tactical handshake challenges the various adverse preferences which should be exposed and dealt with in a joint effort by the relevant actors.

Many of these points have been addressed in the Hollandse IJssel pilot case as described in the next section.

Pilot Case at Hollandse IJssel, The Netherlands: Aligning Investments from a System Perspective

The dikes along the river Hollandsche IJssel are managed by the regional water authority (HHSK). In 2017, the dikes of HHSK were assessed on their performance (component D of the FAIR Framework, the performance of assets). The dikes did not meet the statutory standard, due to the introduction of new legislation, revised standards, and the incorporation of the failure rate of the storm surge barriers. Especially the height and inner slope stability of the dikes is inadequate.

The Hollandsche IJssel can be isolated from the main water system by a storm surge barrier, managed by Rijkswaterstaat, RWS (see Figure 5). This barrier thus controls the hydraulic loads on the dikes and is therefore of pivotal importance for the performance of the system as a whole. In the context of this Pilot Case, an integrated flood risk management analysis has been carried out by HHSK and RWS for the entire river system of the Hollandsche IJssel including the barrier (component 1 of the FAIR Framework, the performance of the network). The SPR Framework ( 1 and 4 in the FAIR framework) was used to develop a mutual understanding of the system performance, which was complemented by a model analysis.

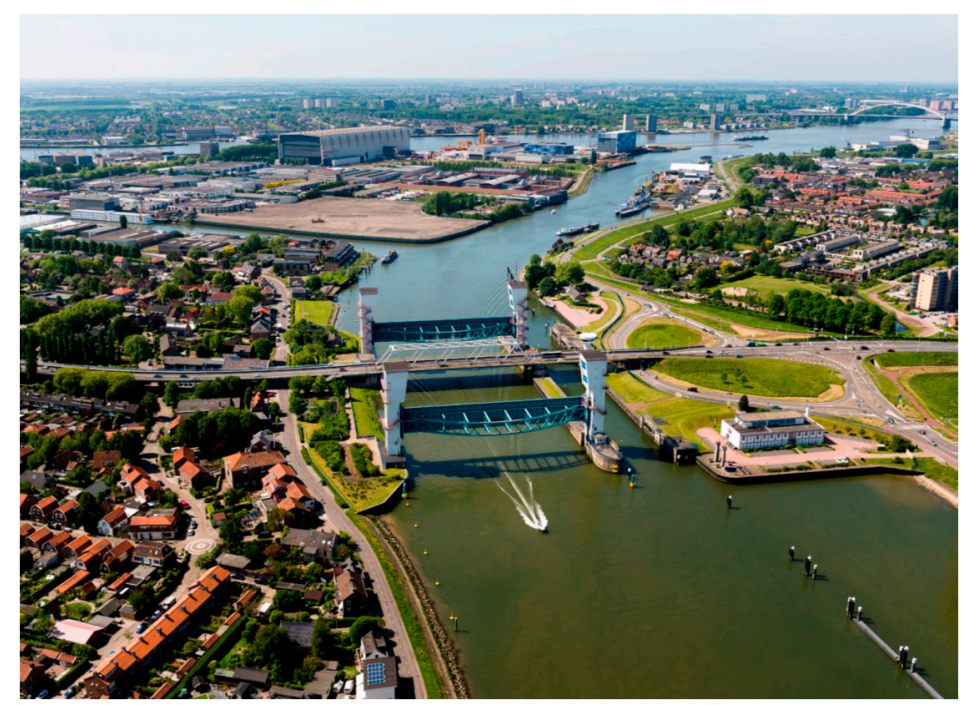

Figure 5. The Hollandse IJssel storm surge barrier as it protects the Hollandse IJssel located behind it. Courtesy Rijkswaterstaat, mediatheek.

The main outcome is that improvements to storm surge barrier reliability will reduce hydraulic loads on the dikes and thus reduce the required (future) investments in dike reinforcement. To achieve 
this additional investment in the barrier is needed, but funding is only available for dike reinforcement by the regional water authority, which is a clear barrier for implementation.

However, after the findings from the Pilot Case, the regional water authority and Rijkswaterstaat proposed an exchange of means to the main funding authority, which is now in the process of getting final approval. The expected reduction in system life-cycle cost is expected to be $\sim 5 \%$, making this case a clear example of how "breaking free from the silo" might lead to more efficient (tactical) asset management. More information on this case study can be found in [30].

\section{Discussion}

\subsection{Outputs, Outcomes and Beneficial Effects}

Application of the FAIR framework in the cases has helped to refine the framework and evaluate the effectiveness in highlighting and defining the details of the strategic, tactical and operational contexts for AM. The FAIR findings can be divided into three categories: outputs, outcomes and beneficial effects. Here, we define outputs as improved approaches, methods and guidance for AM of flood protection infrastructure. Outcomes are defined as improvements to existing practice, learning or other insights from the usage of the FAIR outputs. Beneficial effects are considered the broader, longer-term benefits, such as flood risk reduction, from applying the FAIR framework.

Pertaining to the strategic context of AM, outputs included a demonstration of adaptation planning as a means for proactive planning for uncertain futures, and demonstration of Source-Pathway-Receptor and whole systems approaches as practical means for structuring system risk analysis. The outcome of this is improved understanding and consequently better planning by asset owners, as was illustrated by the adaptive planning approach used in Ribe, Denmark. Over the longer term, this is expected to lead to reduced lifecycle cost and better return on investments due to better targeting of expenditure and cost-sharing, an extension of asset lifetime due to intensified maintenance, and/or increased functionality through collaborative planning and connecting investments across functions. Some of these beneficial effects have already been found in the case on the Hollandse IJssel, The Netherlands.

The output in the tactical AM context included the establishment of institutional perspectives beyond the immediate management scope, which helped in overcoming challenges of cross-utility and multifunctional use. The outcome that followed was the acknowledgement that providing an overview of all functions of flood protection should become a component in the procedure for asset rehabilitation projects. Over the longer term, this is expected to create support and benefits for all stakeholders and lifecycle cost reduction by pooling investments across different functions. An example of the potential of overcoming these challenges was found for the Hollandse IJssel flood protection system, where further integration of management and budgeting of different system interventions (i.e., improvement of flood defences and storm surge barrier) can lead to more efficient asset management strategies on a network level. The expected cost savings of $5 \%$ are in line with the findings of the ROBAMCI (Risk and Opportunity Based Asset Management for Critical Infrastructures) research programme [31]. Here, several cases of asset management of public infrastructures in The Netherlands were investigated, and cost savings were found to be between $5-20 \%$. Within FAIR, for the case of Middelkerke (Belgium) even larger cost savings were found $(26-38 \%)$, as the asset management perspectives lead to a design of the sea defence that was more efficient from a life-cycle perspective [16].

Operational AM outputs included the promotion and illustration of different methods for performance assessment, ranging from simple in situ technical inspections to comparatively complex methods. In addition, it was demonstrated that accounting for the important feedback loop from the maintenance to the design and construction, helps to improve the design of flood protection assets. Furthermore, guidance on maintenance strategies and monitoring processes was provided. Klerk et al. [32] explored the life cycle cost reduction through head monitoring for flood defences and found these to be up to $50 \%$ for the considered cases. The guidance provided in FAIR supported asset owners in developing an asset maintenance approach that includes the portfolio of assets and the 
interacting systems. Over the longer term, it is expected that maintenance efforts can be planned more efficiently. Reform of the asset maintenance approach in Hamburg (Germany) reduced the required maintenance budget by $5 \%$. In addition, efficiency will likely increase further if communication between inspectors, maintenance (maintainers), and designers is improved. This can be supported through systems such as the Dike Information System now employed in Hamburg.

\subsection{Challenges}

Despite the beneficial value of applying the framework, the FAIR cases have demonstrated that there remain considerable challenges for asset management.

Firstly, the institutional context for flood defence asset management is often fragmented. The multifunctional context of flood defences requires alignment across a range of organizations, for example including those that manage transportation, urban development and ecosystems [22,33], or even different parts of the water system (e.g., the Hollandse IJssel pilot study). Furthermore, the cases show that the institutional responsibilities and sources of finance for different AM stages across the FAIR framework are fragmented. For example, dikes may be owned and maintained by private parties (e.g., Denmark) or by local/regional authorities (e.g., Sweden), whilst strengthening measures are (partially) funded by the national government. This can be a barrier for efficient asset management [5].

Secondly, funding is constrained, especially for maintenance and monitoring. Ageing flood defence infrastructure across the North Sea Region requires large investments to keep flood defences up to standard. Unsurprisingly, there is a bias towards construction, with financing primarily being directed towards capital expenditures for strengthening the weakest links in flood defence systems. However, the cases suggest that greater priority may be needed for financing operational AM, especially where the assets are multifunctional. Through that, a more optimal balance of performance, costs and risks across the lifecycle of flood defences might be achieved [32,34].

Thirdly, decisions taken today have longstanding implications. Changing conditions can lead to infrastructure that may be unnecessarily costly, maladapted or regrettable as the reality of the future unfolds [35]. The cases illustrate that this poses several challenges for decision making about the size, nature and timing of investments. These complex decisions become even more difficult when the long-term choices (that take account of future uncertainties in climate and socioeconomic contexts) clash with short-term political realities and varying perceptions of risk. Therefore explicitly accounting for adaptiveness in flood defence asset management is required, and as such, there is a need for actionable tools for adaptive planning, flexible strategies and assets that can be modified in the face of uncertainty [36,37].

Fourthly, strategic planning and operational processes often have little or no interaction. For instance, the case of the Hollandse IJssel clearly demonstrates that regret investments can only be avoided when strategic and operational perspectives closely interact via the tactical handshake. However, alignment is not straightforward, due to the different orientations of strategic and operational $\mathrm{AM}$, and as responsibilities are often distributed among different organizations. Whilst strategic perspectives are focused on continuous learning to anticipate and gain new insights, uncertain future conditions and system performance e.g., [38], operational perspectives are typically task-oriented and therefore more straightforward in terms of clarity of scope, needs and direction e.g., [39].

Fifthly, innovation is not consistently embedded in standard practice. Although the cases have demonstrated various technological and process innovations, it is apparent that innovations, or an innovative culture, are not consistently embedded in standardized AM working processes across the NSR. This results in missed opportunities in terms of minimising life cycle cost, ensuring landscape compatibility, public acceptance, and the ability to monitor and maintain asset performance. For example, rudimentary data collection regarding asset condition often lags behind ongoing developments in data collection and data management. As a result, asset operators struggle to seize the opportunities brought by new technologies. 


\section{Conclusions}

Flood protection asset management aims to balance investment costs, performance and risks throughout the whole life cycle. However, practical application is challenging due to the fragmented institutional organization, lack of integration between strategic and operational contexts of asset management and lack of flexibility towards strategic adaptation as well as innovation on a more general level.

To support tackling these challenges, a framework has been developed in the FAIR project that aligns different asset management components to better align interventions, both on asset- and system-level such that the desired balance between cost, performance and risk is achieved. The FAIR framework (Figure 1) encompasses the essential elements of adaptive asset management and links three decision contexts of asset management: strategic (with the focus on adaptive management planning over the longer term), operational (with the focus on delivering and evaluating the plan), and tactical (focusing on prioritisation and programming, providing the "handshake" between strategy and operation).

Five Pilot Cases were undertaken in the FAIR project to test and refine the framework and demonstrate its value and use. Key considerations for these were:

1. The use of an overall integrated long-term system perspective. The outcomes have led to an improved understanding of the constituent components of flood risk, and consequently better planning by and between asset owners, improving their adaptive capacity.

2. The improved alignment of operational asset management activities. These were found to be handled very differently in different countries and cases, although three underlying core aspects could be distinguished: handling multifunctionality; bridging the gap between design and maintenance and operation by using system knowledge and measurements; taking a long-term perspective.

3. The explicit determination of the tactical decision context helps to efficiently translate the strategic plans into the operational context and vice versa. In this translation, prioritisation and programming were found to be key elements, as well as the translation of performance of individual assets into system/network performance.

Application of the FAIR framework in different pilots has demonstrated the applicability of the framework and therefore justifies use by other asset owners in the NSR and beyond. Over the longer term, it is expected that the utilisation of the framework can lead to reduced life cycle costs and enlarged adaptive capacity for a portfolio of assets; better insight into technical and organizational activities and opportunities; and reduced maintenance efforts with more efficient planning over the asset lifetime. Thus, the FAIR project is expected to have helped to improve asset management making a major contribution to flood risk reduction in the NSR and elsewhere.

Author Contributions: Conceptualization and methodology \& writing—original draft: B.V., W.J.K., P.F., B.G., F.d.H., P.J., U.R.C., J.R., P.S., R.A., writing-review and editing: W.J.K., B.V., and R.A., project administration: B.V. All authors have read and agreed to the published version of the manuscript.

Funding: This research was funded by Interreg North Sea Region Programme 2014-2020, grant number 38-2-9-15 for FAIR Project.

Conflicts of Interest: The authors declare no conflict of interest.

\section{References}

1. ISO. NEN-ISO 55001: Asset Management-Management Systems-Requirements (ISO 55001:2014,IDT); NEN: Delft, The Netherlands, 2014.

2. Moubray, J. Reliability-Centered Maintenance, 2nd ed.; Butterworth-Heinemann: Oxford, UK, 1999; ISBN 9780750633581.

3. NEN. NEN-EN 16991:2018 Risk Based Inspection Framework; NEN: Delft, The Netherlands, 2018. 
4. Institute of Asset Management. Asset Management-An Anatomy; Institute of Asset Management: Bristol, UK, 2014.

5. Klerk, W.J.; den Heijer, F. A framework for life-cycle management of public infrastructure. In Life-Cycle of Engineering Systems: Emphasis on Sustainable Civil Infrastructure, Proceedings of the Fifth International Symposium on Life-Cycle Civil Engineering (IALCCE 2016), Delft, The Netherlands, 16-19 October 2016; CRC Press: London, UK, 2016.

6. Jonkman, S.N.; Voortman, H.G.; Klerk, W.J.; van Vuren, S. Developments in the management of flood defences and hydraulic infrastructure in The Netherlands. Struct. Infrastruct. Eng. 2018, 1-16. [CrossRef]

7. Vuik, V. Building Safety with Nature; Delft University: Delft, The Netherlands, 2019.

8. Gersonius, B.; Rijke, J.; Ashley, R.; Bloemen, P.; Kelder, E.; Zevenbergen, C. Adaptive Delta Management for flood risk and resilience in Dordrecht, The Netherlands. Nat. Hazards 2016, 82, 201-216. [CrossRef]

9. Gersonius, B.; Ashley, R.; Pathirana, A.; Zevenbergen, C. Climate change uncertainty: Building flexibility into water and flood risk infrastructure. Clim. Chang. 2013, 116, 411-423. [CrossRef]

10. CEN. ISO 14090:2019 Adaptation to Climate Change; European Committee for Standardization: Brussels, Belgium, 2019.

11. Kwadijk, J.C.J.; Haasnoot, M.; Mulder, J.P.M.; Hoogvliet, M.M.C.; Jeuken, A.B.M.; van der Krogt, R.A.A.; van Oostrom, N.G.C.; Schelfhout, H.A.; van Velzen, E.H.; van Waveren, H.; et al. Using adaptation tipping points to prepare for climate change and sea level rise: A case study in The Netherlands. Wiley Interdiscip. Rev. Clim. Chang. 2010, 1, 729-740. [CrossRef]

12. Haasnoot, M.; Kwadijk, J.; Van Alphen, J.; Le Bars, D.; Van Den Hurk, B.; Diermanse, F.; Van Der Spek, A.; Oude Essink, G.; Delsman, J.; Mens, M. Adaptation to uncertain sea-level rise; how uncertainty in Antarctic mass-loss impacts the coastal adaptation strategy of The Netherlands. Environ. Res. Lett. 2020, 15. [CrossRef]

13. Fuchs, G.H.A.M.; Keuning, I.; Mante, B.R.; Bakker, J.D. A business case of the estimated profit of Life Cycle Management principles. In Life-Cycle of Structural Systems: Design, Assessment, Maintenance and Management; Furuta, H., Frangopol, D.M., Akiyama, M., Eds.; CRC Press: London, UK, 2014.

14. FAIR. A Perspective on the Future of Asset Management for Flood Protection-A Policy Brief from the Interreg North Sea Region FAIR Project. 2019. Available online: https://northsearegion.eu/media/8638/aw_ interreg-policy_a4_web.pdf (accessed on 9 October 2020).

15. Sayers, P.B.; Gersonius, B.; den Heijer, F.; Klerk, W.J.; Fröhle, P.; Jordan, P.; Radu Ciocan, U.; Rijke, J.; Vonk, B.; Ashley, R. Towards adaptive asset management in flood risk management: A policy framework. J. Water Secur. 2020, submitted.

16. FAIR. Adaptive Asset Management for Flood Protection. 2020. Available online: https://northsearegion.eu/ media/13662/fair_end_report-03-06-2020.pdf (accessed on 9 October 2020).

17. ISO. NEN-ISO 55000: Asset Management-Overview, Principles and Terminology (ISO55000:2014 (Corr. 2014-03),IDT); NEN: Delft, The Netherlands, 2014.

18. Sayers, P.B.; Simm, J.D.; Ogunyoye, F.; Meadowcroft, I. Establishing a Performance-based Asset Management System for Flood Defences (PAMS). In Proceedings of the Defra Conference of Flood and Coastal Management, York, UK, 29 June-1 July 2004.

19. Sayers, P.B.; Wallis, M.J.; Simm, J.D.; Baxter, G.; Andryszewski, T. Towards the next generation of risk-based asset management tools. Flood Risk Sci. Manag. 2010, 313-335. [CrossRef]

20. Marlow, D.R.; Burn, S. Effective Use of Condition Assessment within Asset Management. J. Am. Water Works Assoc. 2008, 100, 54-63. [CrossRef]

21. Sayers, P. Evolution of Strategic Flood Risk Management in Support of Social Justice, Ecosystem Health, and Resilience. In Oxford Research Encyclopedia of Natural Hazard Science; Oxford University Press: Oxford, UK, 2017.

22. Hall, J.W.; Meadowcroft, I.C.; Sayers, P.B.; Bramley, M.E. Integrated Flood Risk Management in England and Wales. Nat. Hazards Rev. 2003, 4, 126-135. [CrossRef]

23. Sayers, P.B.; Hall, J.W.; Meadowcroft, I.C. Towards risk-based flood hazard management in the UK. Proc. Inst. Civ. Eng. Civ. Eng. 2002, 150, 36-42. [CrossRef]

24. Radu Ciocan, U.; Anjkær Nielsen, B.; Wiborg Jessen, H.; Jensen, T. Pilot Ribe Polder-A Practice Brief from the Interreg North Sea Region FAIR Project. 2020. Available online: https://northsearegion.eu/media/13398/ribepilot-v7.pdf (accessed on 9 October 2020). 
25. Jordan, P.; Fröhle, P.; Manojlovic, N. Maintenance of Flood Protection Infrastructure in the North Sea Region-An Analysis of Existing Maintenance Strategies. In Proceedings of the Coastal Structures, Hanover, Germany, 30 September-2 October 2019; Goseberg, N., Schlurmann, T., Eds.; Bundesanstalt für Wasserbau: Karlsruhe, Germany, 2019.

26. Jongejan, R.B.; Diermanse, F.; Kanning, W.; Bottema, M. Reliability-based partial factors for flood defenses. Reliab. Eng. Syst. Saf. 2020, 193, 106589. [CrossRef]

27. Kok, M.; Jongejan, R.; Nieuwjaar, M.; Tanczos, I. Fundamentals of Flood Protection; Ministry of Infrastructure and the Environment and the Expertise Network for Flood Protection: The Hague, The Netherlands, 2017.

28. Her Majesty's Treasury. The Green Book: Appraisal and Evaluation in Central Government; Her Majesty's Treasury: London, UK, 2013.

29. Environment Agency. Managing Flood Risk, Condition Assessment Manual; Environment Agency: Bristol, UK, 2012.

30. Konterman, I.; Weijland, M. Pilot Flood Protection Hollandsche IJssel-A Practice Brief from the Interreg North Sea Region FAIR Project. 2020. Available online: https://northsearegion.eu/media/13622/fphij-pilot-0206-20.pdf (accessed on 9 October 2020).

31. Den Heijer, F. ROBAMCI-Eindrapport. 2019. Available online: https://www.robamci.nl/wp-content/uploads/ 2020/03/11201843-000-ZWS-0017_v0.1-ROBAMCI\%20-\%20Eindrapport\%20def\%203\%20mrt\%202020\% 20definitief-met\%20paraaf.pdf (accessed on 9 October 2020).

32. Klerk, W.J.; Schweckendiek, T.; den Heijer, F.; Kok, M. Value of Information of Structural Health Monitoring in Asset Management of Flood Defences. Infrastructures 2019, 4, 56. [CrossRef]

33. Van Herk, S.; Rijke, J.; Zevenbergen, C.; Ashley, R. Understanding the transition to integrated flood risk management in The Netherlands. Environ. Innov. Soc. Transit. 2015, 15, 84-100. [CrossRef]

34. Klerk, W.J.; Kanning, W.; Vos, R.J.; Kok, M. Risk-based maintenance of asphalt revetments on flood defences. In Proceedings of the IALCCE2020, Shanghai, China, 27-30 October 2020.

35. Milly, P.C.D.; Betancourt, J.; Falkenmark, M.; Hirsch, R.M.; Kundzewicz, Z.W.; Lettenmaier, D.P.; Stouffer, R.J. Stationarity Is Dead: Whither Water Management? Science 2008, 319, 573-574. [CrossRef] [PubMed]

36. Bloemen, P.; Reeder, T.; Zevenbergen, C.; Rijke, J.; Kingsborough, A. Lessons learned from applying adaptation pathways in flood risk management and challenges for the further development of this approach. Mitig. Adapt. Strateg. Glob. Chang. 2018, 23, 1083-1108. [CrossRef] [PubMed]

37. Marchau, V.A.W.J.; Walker, W.E.; Bloemen, P.J.T.M.; Popper, S.W. (Eds.) Decision Making under Deep Uncertainty; Springer International Publishing: Cham, Switzerland, 2019; ISBN 978-3-030-05251-5.

38. Butler, J.R.A.; Bergseng, A.M.; Bohensky, E.; Pedde, S.; Aitkenhead, M.; Hamden, R. Adapting scenarios for climate adaptation: Practitioners' perspectives on a popular planning method. Environ. Sci. Policy 2020, 104, 13-19. [CrossRef]

39. Rijke, J.; van Herk, S.; Zevenbergen, C.; Ashley, R.; Hertogh, M.; ten Heuvelhof, E. Adaptive programme management through a balanced performance/strategy oriented focus. Int. J. Proj. Manag. 2014, 32, 1197-1209. [CrossRef]

Publisher's Note: MDPI stays neutral with regard to jurisdictional claims in published maps and institutional affiliations.

(C) 2020 by the authors. Licensee MDPI, Basel, Switzerland. This article is an open access article distributed under the terms and conditions of the Creative Commons Attribution (CC BY) license (http://creativecommons.org/licenses/by/4.0/). 